\title{
Khat chewing increases the risk for developing chronic liver disease: a
}

\section{hospital-based case-control study}

\section{(HEP-17-1830R)}

Authors: Stian Magnus Staurung Orlien, ${ }^{1}$ Irene Sandven, ${ }^{2}$ Nega Belay Berhe, ${ }^{1,3}$ Nejib Yusuf Ismael, ${ }^{4,5}$ Tekabe Abdosh Ahmed, ${ }^{5,6}$ Kathrine Stene-Johansen, ${ }^{7}$ Svein Gunnar Gundersen, ${ }^{8,9}$ Marsha Yvonne Morgan, ${ }^{10}$ Asgeir Johannessen ${ }^{1}$ (D)

Affiliations: ${ }^{1}$ Regional Centre for Imported and Tropical Diseases, Oslo University Hospital Ullevål, Oslo, Norway; ${ }^{2}$ Oslo Centre of Biostatistics and Epidemiology, Oslo University Hospital, Oslo, Norway; ${ }^{3}$ Aklilu Lemma Institute of Pathobiology, Addis Ababa University, Addis Ababa, Ethiopia; ${ }^{4}$ Department of Internal Medicine, Hiwot Fana Specialized University Hospital, Harar, Ethiopia; ${ }^{5}$ Faculty of Medicine, Haramaya University College of Health and Medical Sciences, Harar, Ethiopia; ${ }^{6}$ Department of Internal Medicine, Jugal Hospital, Harar, Ethiopia; ${ }^{7}$ Department of Molecular Biology, Norwegian Institute of Public Health, Oslo, Norway; ${ }^{8}$ Research Unit, Sørlandet Hospital HF, Kristiansand, Norway; ${ }^{9}$ Department of Global Development and Planning, University of Agder, Kristiansand, Norway; ${ }^{10} \mathrm{UCL}$ Institute for Liver \& Digestive Health, University College London, London, UK.

\section{Email addresses:}

SMSO: $\underline{\text { stian@orlien.no }}$

IS: uxsair@ous-hf.no

NBB: nega.berhe.belay@gmail.com

NYI: nejibyusuf@gmail.com

TAA: tekaba321@yahoo.com

This article has been accepted for publication and undergone full peer review but has not been through the copyediting, typesetting, pagination and proofreading process which may lead to differences between this version and the Version of Record. Please cite this article as doi: 10.1002/hep.29809 
KSJ: kathrine.stene-johansen@,fhi.no

SGG: s.g.gundersen@gmail.com

MYM: marsha.morgan@ucl.ac.uk

AJ: johannessen.asgeir@gmail.com

Keywords: Chronic liver disease; drug induced hepatotoxicity; epidemiology.

Correspondence: Dr Asgeir Johannessen, Regional Centre for Imported and Tropical Diseases, Oslo University Hospital Ullevål, PO Box 4956 Nydalen, 0424 Oslo, Norway. Tel: +47

97983264. Fax: +47 22119181. Email: johannessen.asgeir@gmail.com.

List of abbreviations: WHO, World Health Organization; CLD, chronic liver disease; ALT, alanine aminotransferase; AST, aspartate aminotransferase; HBsAg, hepatitis B surface antigen; HCV, hepatitis C virus; ELISA, enzyme-linked immunosorbent assay; OR, odds ratio; CI, confidence interval; AP, attributable proportion; STROBE, Strengthening the Reporting of Observational studies in Epidemiology; HBV, hepatitis B virus; AOR, adjusted odds ratio; HIV, human immunodeficiency virus; IgG, immunoglobulin G; CYP, cytochrome P450; DDT, dichlorodiphenyltrichloroethane.

Financial support: The work was supported by grants from the Norwegian Research Council (grant number 220622/H10) and the South-Eastern Norway Regional Health Authority (grant number 2011068).

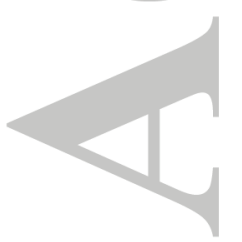




\section{ABSTRACT}

The chewing of the leaves of Catha edulis (khat) has been implicated in the development of liver disease, but no controlled observations have been undertaken. The objective of the present study was to determine whether khat chewing is associated with development of chronic liver disease (CLD). A case-control study was conducted at two public hospitals in Harar, Ethiopia, between April 2015 and April 2016. A consecutive sample of 150 adult hospital attendees with CLD

were included as cases, and 300 adult hospital attendees without clinical or laboratory evidence of CLD were included as controls. Khat consumption was quantified in khat years; one khat year was defined as daily use of 200 grams of fresh khat for one year. A logistic regression model was used to control for confounders. There was a significant association between chewing khat and the risk for developing CLD (crude odds ratio [OR] 2.64; 95\% CI 1.56-4.58). In men, this risk, following adjustment for age, alcohol use, and chronic hepatitis $\mathrm{B} / \mathrm{C}$ infection, increased with increasing khat exposure; thus, compared to never users the adjusted OR for low khat exposure was 3.58 (95\% CI 1.05-12.21), moderate khat exposure 5.90 (95\% CI 1.79-19.44), and high khat exposure 13.03 (95\% CI 3.61-47.02). The findings were robust in a post-hoc sensitivity analysis in which individuals with identifiable risk factors for CLD were excluded. Conclusion: A significant association was observed between chewing khat and the risk for developing CLD. In men, the association was strong and dose-dependent, suggesting a causal relationship. As the prevalence of khat chewing is increasing worldwide, these findings have major public health implications.

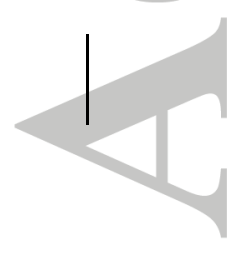




\section{MAIN TEXT}

The leaves and shoots of the evergreen shrub Catha edulis (khat) are chewed to reduce fatigue, increase performance and for its pleasurable effects, which include euphoria, loquacity and

excitement. Khat chewing is common in the Horn of Africa, the Arabian Peninsula and the East Coast of Africa where it has been part of the social and cultural heritage for centuries.(1) Over the past three decades khat has become increasingly available world-wide and its use perpetuated and even adopted by the wider diaspora.(2) The global prevalence of khat chewing is unknown; the proposed figure of 20 million daily users is probably an underestimate.(3)

Khat leaves, typically 100-300 grams, are chewed in sessions lasting several hours and the juice of the masticated leaves is swallowed. The contained alkaloids, of which cathinone (aminopropiophenone) is the most important, are extracted during chewing; the buccal mucosa plays a major role in the absorption.(4) The state of alertness and euphoria associated with khat usage is most likely induced by cathinone, which exerts effects on the central nervous system similar to those of amphetamine. $(4,5)$

The World Health Organization (WHO) has defined khat as a drug of abuse as it may lead to health and social problems. Chronic khat use is associated with psychological adverse effects, including psychosis and exacerbation of pre-existing psychotic disorders.(6) Khat users may also exhibit dependence; however in the majority of users the degree of associated physical dependence is low although the levels of psychological dependence may be substantial.(5)

Khat chewing is also associated with a number of somatic health sequelae, including myocardial infarction, systemic hypertension, upper gastrointestinal cancers, cognitive impairment and impaired foetal growth.(7) Khat has also been implicated in the development of both acute hepatitis (8-12) and chronic liver disease (CLD) (13-16) in several case series. Chapman et al. 
reported on six patients of Somali origin, living in the United Kingdom, in whom khat abuse was implicated in the development of fulminant hepatic failure.(12) Stuyt et al. reported unexplained CLD in six male immigrants from Somalia and Ethiopia living in the Netherlands and noted their history of chronic khat use.(14) However, since khat is illegal in Europe, North America and Australia, and the users are mainly from closed immigrant communities, no controlled observations are available.

Decompensated CLD is one of the most frequent reasons for admission to medical wards in eastern Ethiopia; in more than $50 \%$ of the cases the liver disease is 'unexplained'.(16) Khat chewing is widespread throughout the country but more especially in the eastern regions where khat cultivation predominantly takes place.(17,18) The number of people chewing khat has increased rapidly in recent years with the habit gaining popularity in all segments of the community; hence, the overall prevalence of khat chewing in Ethiopia is estimated at $15.3 \%$ but with wide regional variations.(18) Although khat chewing is traditionally a male habit, a recent community-based study in pregnant women in eastern Ethiopia reported a prevalence of khat usage of $34.6 \% .(19)$

The aim of the present study was to determine the association between use of khat and the risk for developing significant CLD in eastern Ethiopia, using a case-control design exercising controls for potential confounding variables. 


\section{MATERIAL AND METHODS}

\section{Study setting and participants}

This prospective, hospital-based, case-control study was undertaken between April 2015 and April 2016 in Harar, eastern Ethiopia. Inpatients and outpatients attending two large public hospitals, the Jugal Hospital and the Hiwot Fana Specialized University Hospital, were eligible for inclusion. Medical sub-specialty services are not available in either hospital; thus, all patients with CLD attend a general medical outpatient clinic and, if admitted, are housed on a general medical ward.

The cases comprised of adult ( $\geq 18$ years of age) outpatients and inpatients with a new diagnosis of CLD defined, for purposes of this study, as: (i) the presence of clinical features suggestive of decompensated liver disease viz ascites, jaundice and/or hepatic encephalopathy; and (ii) the presence, on ultrasound, of hepatic parenchyma heterogeneity and/or surface irregularity.

Patients presenting with severe acute hepatitis defined as liver injury of $<6$ weeks duration, serum alanine aminotransferase (ALT) activity of $>100 \mathrm{U} / \mathrm{L}$, and the absence of coarsened echotexture and surface irregularity on ultrasonography, were excluded. Also excluded were patients with a previously established diagnosis of CLD or with liver dysfunction secondary to alternative conditions viz congestive cardiac failure, hepatic malignancies, biliary obstruction and septicaemia.

As khat use is associated with a number of adverse medical and psychiatric sequelae, controls could not be selected from amongst the general medical or psychiatric populations. The controls therefore comprised of adult hospital outpatients or inpatients under the care of the ophthalmology, dermatology or surgical services, none of whom had a history or clinical evidence of CLD or a serum ALT above the upper limit of the laboratory reference range of 40 $\mathrm{U} / \mathrm{L}$. 


\section{Patient assessment}

All patients were assessed using standardized checklists and semi-structured interviews to gather information on predetermined demographic and clinical variables. The interviews were conducted by local nurses fluent in the native language of the study participants, and the interviewers were blinded to the disease status of the interviewees. Neither the study subjects nor the interviewers were told that the study hypothesis was of a likely association between khat chewing and the development of CLD.

Information on the use of khat was obtained and quantified in grams using a visual analogue scale. The frequency of khat chewing was categorized using the Drug Use Disorders Identification Test (DUDIT).(20) The frequency and duration of khat usage was used to classify lifetime khat exposure in 'khat years'. One khat year was defined by daily use of 200 grams of fresh khat for one year. Exposed subjects were defined as all past or current khat users, regardless of the amount chewed. Those who had never used khat were defined as 'never users'.

Information on the frequency and quantity of previous and current alcohol use was obtained using a frequency/quantity questionnaire; average daily intake was quantified in grams using the following equation:

Alcohol concentration by volume x $0.78 \times$ volume consumed $(\mathrm{ml}) / 100$

where alcohol concentration by volume is the percentage alcohol content of the local alcoholic beverages,(21) and 0.78 is the specific gravity of alcohol. Alcohol abuse was defined as consumption of $>20$ grams/day for women and $>30$ grams/day for men.(22) Exposed subjects were defined as past or current users of alcohol, regardless of the amount consumed.

Clinical examination was conducted after the patient interview using a pre-specified standard.

Particular note was made of any features suggestive of CLD including cutaneous and peripheral liver stigmata and features of hepatic decompensation. 


\section{Laboratory tests}

Blood was collected by venipuncture, and the serum and plasma were separated within two hours and aliquots stored at $-20^{\circ} \mathrm{C}$ until analyzed. Routine blood tests including serum ALT and aspartate aminotransferase (AST) activities were analyzed using a semi-automatic biochemistry analyzer Dirui DR-7000D (DIRUI, Changchun, China) and HumaLyzer 3000 (HUMAN, Wiesbaden, Germany). Hepatitis B surface antigen (HBsAg) screening was undertaken locally using the WHO approved rapid diagnostic test Determine ${ }^{\mathrm{TM}}$ (Alere, Waltham, MA, USA); hepatitis $\mathrm{C}$ virus (HCV) antibody (anti-HCV) screening was undertaken locally using the WHO approved rapid diagnostic test SD BIOLINE HCV (Standard Diagnostics, Yongin-si, Republic of

Korea). All sera were subsequently transported on ice to Aklilu Lemma Institute of Pathobiology in Addis Ababa for confirmatory testing of HBsAg and anti-HCV using an enzyme-linked immunosorbent assay (ELISA) method (Elisys Uno, HUMAN, Wiesbaden, Germany; or Architect, Abbott Diagnostics, IL, USA). Discrepancies between rapid tests and ELISA results were resolved using a second ELISA assay (Architect; or Bio-Rad, Hercules, CA, USA).

\section{Abdominal imaging}

Abdominal ultrasonography was undertaken, to a pre-determined standard, by a local radiologist using a 3.5 MHz convex transducer Aloka Flexus SSD-1100 (Aloka, Tokyo, Japan). The diagnosis of CLD was based on the presence of an irregular liver surface and/or liver parenchyma heterogeneity.(23) Other features suggestive of the presence of CLD such as ascites, splenomegaly and a collateral circulation were also noted and recorded.

\section{Sample size calculation}

A sample size estimation was performed a priori based on the inclusion of two controls per case, and the conventional type I error of $5 \%$ and power of $80 \%$. Based on an estimated prevalence of 
daily khat use of $20 \%,(24)$ and the assumption that khat use would be at least twice as common in cases as in controls (odds ratio [OR] 2.00), a minimum of 137 cases and 274 controls would be needed for an adequately powered study. Individuals with other risk factors for CLD were retained in the main analysis, since it was assumed that khat chewing could act as either a sole or an adjuvant cause of liver injury.

\section{Statistical methods}

Categorical variables were summarized as frequencies, and continuous variables by the median and interquartile range. Comparisons between the cases and controls were performed using the Mann-Whitney U test for continuous variables and Pearson Chi-Square test for categorical variables.

An explanatory strategy investigating the association between khat chewing and CLD was undertaken and quantified as OR with its 95\% confidence interval (CI).(25) An initial stratified analysis evaluated effect modification (interaction) and confounding by other variables considered in the protocol. A Breslow and Day test of homogeneity between strata was performed to pinpoint effect modification (interaction). Confounding was controlled univariately using the Mantel-Haenszel method. The magnitude of the confounding effect was evaluated by comparing the crude OR and the adjusted Mantel-Haenszel OR. When cells contained zero counts, a value of 0.5 was added to each cell frequency before calculating the stratum-specific OR and the Mantel-Haenszel summary OR. A logistic regression model was used to control for multiple confounders and the presence of effect modification.(25) The relationship between levels of khat exposure and the risk for developing CLD was explored by: (i) using a chi-square test for trend with khat exposure categorized by khat year quartiles; and (ii) using the per unit increase in khat years as a continuous variable in the logistic regression model.

The attributable proportion (AP) was estimated as: 
$A P=\frac{P e(\mathrm{OR}-1)}{P_{e}(\mathrm{OR}-1)+1}$

where $P_{\mathrm{e}}$ is the prevalence of khat exposure in the target population.(26)

A post hoc sensitivity analysis was performed excluding all cases of CLD with an identifiable aetiology after a comprehensive panel of tests, which included parasitology and serological testing for viral, autoimmune, and genetic liver diseases.(16) The controls did not undergo the same comprehensive panel of tests, nor abdominal ultrasound, but all had serum ALT activities $<40 \mathrm{U} / \mathrm{L}$ and were screened for the risk factors assumed a priori to be the most relevant viz alcohol abuse and viral hepatitis; those with a history of alcohol abuse or evidence of chronic hepatitis B and C infection were excluded from the sensitivity analysis.

The statistical analyses were performed in STATA 14.0 (StataCorp, College Station, TX, USA).

The study was compliant with the Strengthening the Reporting of Observational Studies in Epidemiology (STROBE) statement guidelines.(27)

\section{Ethics}

The study was conducted in accordance with the Declaration of Helsinki,(28) and was approved by the National Research Ethics Review Committee (Ref. No.: 3.10/829/07) in Ethiopia and by the Regional Committees for Medical and Health Research Ethics (Ref. No.: 2014/1146) in Norway. Written informed consent was obtained from all study subjects. 


\section{RESULTS}

\section{Characteristics of the study population}

A total of 244 potential cases and 370 controls were screened for inclusion. The final study population comprised of 150 cases with CLD and 300 controls without liver disease (Figure 1).

Of these, $31(20.7 \%)$ cases and 265 (88.3\%) controls were outpatients, while $119(79.3 \%)$ cases and $35(11.7 \%)$ controls were inpatients. The cases were significantly more likely than the controls to be male, Muslim, non-drinkers of alcohol, HBsAg positive and to use khat (Table 1). Men were more likely than women to be HBsAg positive, both among cases (41.7\% vs. $23.8 \%$; $p=0.042)$ and controls $(9.9 \%$ vs. $3.9 \% ; p=0.049)$. Moreover, the proportion reporting current or previous khat use was significantly higher among men than women (cases: $96.3 \%$ vs. $54.8 \%$; $p<0.001$; controls: $77.9 \%$ vs. $53.9 \%$; $p<0.001)$. The median level of khat exposure was also significantly higher in men compared to women (Table 1).

\section{Association between khat exposure and CLD}

In univariable analysis, there was a significant association between chewing khat and the risk for developing CLD (crude OR 2.64; 95\% CI 1.56-4.58; $p<0.001$ ). The magnitude of the risk estimate wăs different in men and women (Table 2). Chronic hepatitis B virus (HBV) infection had a considerable confounding effect on the risk estimate (18\%), whereas the effects of age $(2 \%)$ and alcohol consumption (3\%) were minimal. The variable HCV-infection contained too few positive results to be included in both stratified and multivariable analyses.

The final multivariable analysis showed that the effect of khat on the risk for developing CLD was dependent on its interaction with sex when adjusting for age, alcohol use, and chronic HBVinfection (interaction khat*sex; $p=0.013$ ). The effect was strong in men (adjusted odds ratio [AOR] 5.67; 95\% CI 1.85-17.37; $p=0.002$ ), but not evident in women (AOR 1.04; 95\% CI 0.49$2.19 ; p=0.922)$. 
An upward trend in the risk for developing CLD with increasing khat exposure was found after adjusting for $\mathrm{HBV}$-infection, alcohol use and age; this was indicative of a dose-response relationship in men, but not in women (Table 3). When khat exposure was employed as a continuous variable in the logistic regression model, the findings pointed in the same direction; per 1 khat year increment, the odds of CLD was significantly increased in men (AOR 1.007; 95\% CI 1.001-1.013; $\mathrm{p}=0.019$ ), but not in women (AOR 1.012; 95\% CI 0.998-1.027; $\mathrm{p}=0.102$ ).

\section{Proportion of CLD attributable to khat exposure}

Assuming that the relationship between khat exposure and the risk for developing CLD is causal, more than half of the CLD cases in this study population were attributable to khat usage (AP $52.6 \%$; 95\% CI 33.1-72.0). This effect showed marked difference in relation to sex; in men, the AP was $83.2 \%$ (95\% CI 66.4-100) while in women it was only $1.9 \%(95 \%$ CI -35.6-39.3).

\section{Sensitivity analysis}

Seventy (46.7\%) of the 150 cases and $31(10.3 \%)$ of the 300 controls had documented risk factors for CLD other than khat use (S1 Figure). The remaining 80 (53.3\%) cases and 269 $(89.7 \%)$ controls had no identifiable risk factors for CLD except that $66(82.5 \%)$ and 178 (66.2\%), respectively, were regular khat users (S1 Table).

The significant association between khat use and the risk for developing CLD was robust in this subpopulation of 80 cases and 269 controls (crude OR $2.41 ; 95 \%$ CI $1.25-4.90 ; p=0.005$ ). The sex differences were slightly more pronounced than in the total cohort (S2 Table). No other significant confounders were identified.

The upward trend in the risk for developing CLD with increasing khat exposure observed in the primary analysis persisted in the sensitivity analysis, with findings indicative of a dose-response relationship in men, but no such relationship in women (S3 Table). Similarly, the findings from the primary analysis when khat exposure was analyzed as a continuous variable were reproduced 
in the sensitivity analysis; per 1 khat year increment, the odds of CLD was significantly increased in men (AOR 1.008; 95\% CI 1.001-1.015; $\mathrm{p}=0.034)$, but not in women (AOR 1.014;
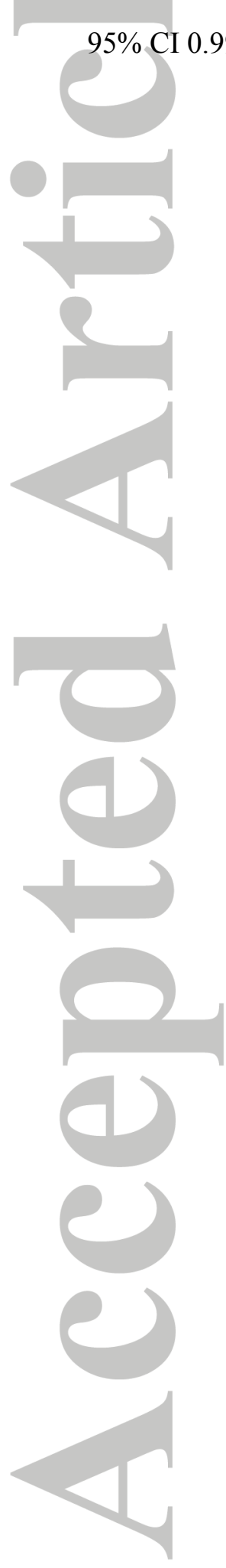

Hepatology

This article is protected by copyright. All rights reserved. 


\section{DISCUSSION}

A strong and significant association was observed, in the present study, between chewing khat and the risk for developing CLD. No risk factors for liver injury were identified in $53 \%$ of the cases with CLD despite extensive investigations, except that more than $80 \%$ of them used khat. Additionally, although confined to men, a clear dose-response relationship was observed between khat exposure and the associated risk for CLD. In previous case reports, resolution of the liver injury has been recorded following cessation of khat, whilst relapse following reexposure has also been documented.(9,12,13) Moreover, khat has been shown to be hepatotoxic in animals manifesting as a spectrum of liver injury.(29-31) Evidence from the present study, together with previous case reports and animal studies, supports a strong association and suggests a causal relationship between khat chewing and the development of CLD.

The mechanism of the khat-related hepatotoxicity is unknown, but several plausible biological explanations have been proposed. First, although there were no compelling features of an autoimmune process in the cases in the present study, previous case reports have documented low titers of autoantibodies and histological features reminiscent of an autoimmune hepatitis in patients suspected of having khat-related liver injury.(9,10,32) Second, the khat-related alkaloids are metabolized extensively in the liver via the enzyme CYP2D6 and have short halflives. $(4,33)$ The finding in one case series of very high concentrations of khat alkaloids in a sample of explanted liver many weeks after the last exposure to khat suggests that accumulation of khat and/or its metabolites may be important.(12) Thus, polymorphisms in the gene controlling CYP2D6 may play a role in determining individual susceptibility to khat-related liver injury, as may possession of variants in other genes implicated in the risk for developing CLD per se.(34) Third, the possibility that the liver injury might not relate to khat itself, but to contaminants such as herbicides and pesticides or to contamination with heavy metals or toxogenic fungae, has to be considered but is thought to be unlikely. $(35,36)$ Rodents given diets 
containing uncontaminated khat leaves showed elevated liver enzymes and necroinflammatory change on histology, supporting the contention that the natural substances contained in khat leaves are responsible for the hepatic injury.(29,30) Finally, khat has been shown to trigger generation of reactive oxygen species in human cells in vitro resulting in hepatocyte apoptosis.(37) Similar histological features have been described in man following ingestion of ecstasy, another amphetamine-related drug.(38)

There is no obvious explanation for the observed sex differences in the susceptibility to khatrelated liver injury observed in the present study. Khat usage was generally lower in women than men, but even women with moderate or high-level khat exposure did not seem to be at significantly increased risk of CLD. This apparent differential susceptibility to khat-related hepatotoxicity could be explained by one or more of the following: (i) the levels of exposure in women may not reach the threshold for toxicity; (ii) there are sex-differences in chewing habits which might influence the duration of exposure; men spend concentrated blocks of recreational time chewing khat and hence the duration of exposure is prolonged, while women tend to chew khat intermittently so that the duration of overall exposure is much shorter; (iii) exposure to certain dietary or environmental agents may result in either induction or inhibition of CYP2D6 activity resulting in changes in khat metabolism; sex-specific differences in exposure to these agents may, therefore, play a role; it is also possible that there may be sex-specific differences in the number of copy variants of CYP2D6 or differences in the frequency of variant single nucleotide polymorphisms. None of these possibilities, however, can be addressed utilizing the data from the present study.

This study had a number of strengths. First, data were collected over a one-year period, thereby controlling for possible seasonal variations in khat availability and hence exposure. Second, by using newly diagnosed cases, the exposure-disease relationship was less likely to be influenced by altered risk habits, lifestyle change or other interventions based on previous medical 
advice.(25) Finally, there were no missing data either for the main exposure variables or the potential confounders.

The study also had its limitations. First, selection bias cannot be excluded; an unknown proportion of patients with CLD may not have been seen by the recruiting medical services for a variety of practical, cultural and socioeconomic reasons. In addition, the decision to use hospital patients as controls might have introduced Berkson's bias,(25) as their attendance could have been affected by both exposure and disease. An attempt was made to minimize this risk by the selection of control subjects from a range of hospital departments, and not from specialties dealing with illnesses known to be associated with khat usage. $(7,39,40)$ However, this may inadvertently have resulted in introduction of possible bias as the majority of the controls were outpatients and the majority of the cases inpatients, and we cannot be sure whether this potential bias goes towards or away from the null.

Second, as in any case-control study, information bias cannot be excluded. Under-reporting or denial of alcohol consumption or other recreational drugs is common in observational studies and may result in an underestimation of the degree of confounding. The fact that the cases in the present study reported less exposure to alcohol may suggest information bias, but it more likely reflects the fact that the majority of the cases were Muslims compared with only two thirds of the controls. Of note, the 2016 Ethiopian Demographic and Health Survey reported a prevalence of abstinence from alcohol of $86.6 \%$ in the Harari region,(41) and thus the high abstinence rate in the present study seems representative. Although data from Ethiopia are scarce, the small proportion of people with alcohol-related CLD in the present study is in line with previous findings. $(42,43)$ The use of khat in eastern Ethiopia, on the contrary, is legal and socially accepted, and its usage less likely to be underreported in this context. Since neither the study subjects nor the interviewers were informed about the primary aim of this study, any 
misclassification of khat exposure is likely to be non-differential, so the observed effect of khat on the development of CLD would, if anything, be underestimated.(25)

Third, abdominal ultrasound was not performed in the controls and hence some may have had undiagnosed CLD. However, undiagnosed cirrhosis is rare in the general population, usually $<1 \%$ of adults in population-based studies, $(44,45)$ so it is unlikely that this would have affected our results significantly.

Fourth, power deficiency might be one explanation why women appeared less susceptible to khat-related liver injury, as relatively few women reported high-level khat exposure.

Finally, we cannot exclude residual confounding by factors not accounted for in our analysis, such as cigarette smoking, coffee intake, the use of traditional herbal remedies, exposure to dichlorodiphenyltrichloroethane (DDT) and other potentially hepatotoxic pesticides through consumption of unwashed khat leaves. $(46,47)$

In conclusion, a strong and significant association was observed between khat chewing and CLD, strengthening the hypothesis that khat is implicated in the development of CLD. In men, the association was strong and dose-dependent suggesting a causal relationship. This study identified khat-associated chronic liver disease that may be responsible for a significant proportion of the liver disease observed in countries where khat use is widespread. As the prevalence of khat chewing is expanding within the wider diaspora, these findings have important public health implications.

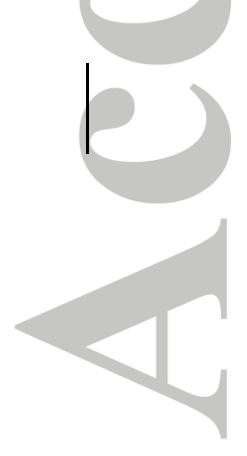




\section{ACKNOWLEDGEMENTS}

We acknowledge the help, support and expertise of the hospital staff at the Jugal Hospital and the Hiwot Fana Specialized University Hospital in Ethiopia, in particular the laboratory technicians, radiologists and physicians. We would also like to thank the staff at the Harari Health Research and Regional Laboratory and the Aklilu Lemma Institute of Pathobiology in Ethiopia, and the Department of Medical Biochemistry at Drammen Hospital and the Department of Virology at the Norwegian Institute of Public Health in Norway for their help and dedication. We are grateful for the support received from the Harari Regional Health Bureau and the Haramaya University College of Health and Medical Sciences in Ethiopia. Finally, we are indebted to the patients who participated so willingly in the study.

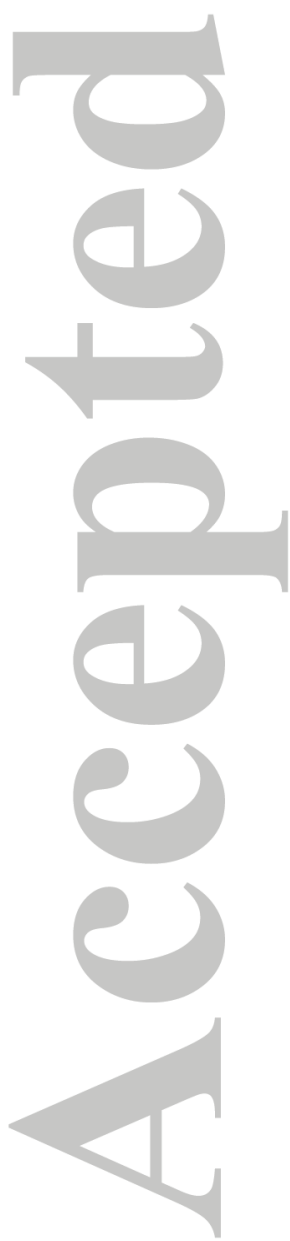




\section{REFERENCES}

1. Krikorian AD. Kat and its use: an historical perspective. J Ethnopharmacol 1984;12:115-

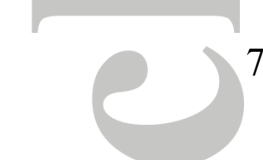

2. Odenwald M, Klein A, Warfa N. Introduction to the special issue: the changing use and misuse of khat (Catha edulis)--tradition, trade and tragedy. J Ethnopharmacol

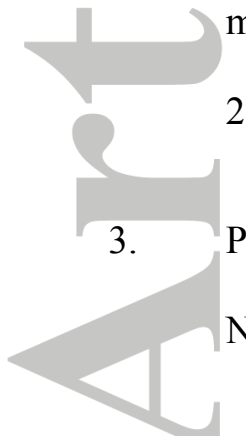

4. Toennes SW, Harder S, Schramm M, Niess C, Kauert GF. Pharmacokinetics of cathinone, cathine and norephedrine after the chewing of khat leaves. Br J Clin Pharmacol 2003;56:125-30.

5. Feyissa AM, Kelly JP. A review of the neuropharmacological properties of khat. Prog Neuropsychopharmacol Biol Psychiatry 2008;32:1147-66.

6. Odenwald M, Neuner F, Schauer M, Elbert T, Catani C, Lingenfelder B, et al. Khat use as risk factor for psychotic disorders: a cross-sectional and case-control study in Somalia. BMC Med 2005;3:5.

7. Corkery JM, Schifano F, Oyefeso A, Ghodse AH, Tonia T, Naidoo V, et al. Overview of literature and information on "khat-related" mortality: a call for recognition of the issue and further research. Ann Ist Super Sanita 2011;47:445-64.

Yildiz H, Komuta M, Monsalve C, Starkel P, Lefebvre C. To chew or not to chew: that's the question. Acta Clin Belg 2016;71:187-9. 
9. Forbes MP, Raj AS, Martin J, Lampe G, Powell EE. Khat-associated hepatitis. Med J Aust 2013;199:498-9.

10. Riyaz S, Imran M, Gleeson D, Karajeh MA. Khat (Catha edulis) as a possible cause of autoimmune hepatitis. World J Hepatol 2014;6:150-4.

11. Brostoff JM, Plymen C, Birns J. Khat--a novel cause of drug-induced hepatitis. Eur J Intern Med 2006;17:383.

12. Chapman MH, Kajihara M, Borges G, O'Beirne J, Patch D, Dhillon AP, et al. Severe, acute liver injury and khat leaves. NEJM 2010;362:1642-1644.

13. Peevers CG, Moorghen M, Collins PL, Gordon FH, McCune CA. Liver disease and cirrhosis because of khat chewing in UK Somali men: a case series. Liver Int 2010;30:1242-3.

14. Stuyt RJ, Willems SM, Wagtmans MJ, van Hoek B. Chewing khat and chronic liver disease. Liver Int 2011;31:434-6.

15. Mahamoud HD, Muse SM, Roberts LR, Fischer PR, Torbenson MS, Fader T. Khat chewing and cirrhosis in Somaliland: Case series. Afr J Prim Health Care Fam Med 2016;8:e1-4.

16. Orlien SMS, Berhe N, Yusuf N, Abdosh T, Gundersen SG, Johannessen A. Unexplained chronic liver disease in Eastern Ethiopia: a cross-sectional study [Abstract]. Hepatology 2016;64(Suppl):1834A.

17. Gebissa E. Taking the place of food: Khat in Ethiopia. Trenton, N.J.: Red Sea Press, 2010. 
18. Haile D, Lakew Y. Khat chewing practice and associated factors among adults in Ethiopia: Further analysis using the 2011 demographic and health survey. PLoS One 2015; $10: \mathrm{e} 0130460$.

19. Kedir H, Berhane Y, Worku A. Khat chewing and restrictive dietary behaviors are associated with anemia among pregnant women in high prevalence rural communities in eastern Ethiopia. PLoS One 2013;8:e78601.

20. Berman AH, Bergman H, Palmstierna T, Schlyter F. Evaluation of the Drug Use Disorders Identification Test (DUDIT) in criminal justice and detoxification settings and in a Swedish population sample. Eur Addict Res 2005;11:22-31.

21. Ashenafi M. The microbiology of Ethiopian foods and beverages: A review. SINET: Ethiop J Science 2002;25:97-140.

22. Schiff ER, Sorrell MF, Maddrey WC. Schiff's diseases of the liver. Philadelphia: Lippincott Williams \& Wilkins, 2007.

23. Allan R, Thoirs K, Phillips M. Accuracy of ultrasound to identify chronic liver disease. World J Gastroenterol 2010;16:3510-20.

24. Reda AA, Moges A, Biadgilign S, Wondmagegn BY. Prevalence and determinants of khat (Catha edulis) chewing among high school students in eastern Ethiopia: a crosssectional study. PLoS One 2012;7:e33946.

25. Kleinbaum DG, Kupper LL, Morgenstern H. Epidemiologic research: principles and quantitative methods. Belmont, CA: Lifetime Learning Publications, 1982.

26. Elwood M. Critical appraisal of epidemiological studies and clinical trials. New York, NY: Oxford University Press, 2017. 
27. von Elm E, Altman DG, Egger M, Pocock SJ, Gotzsche PC, Vandenbroucke JP, et al. The Strengthening the Reporting of Observational Studies in Epidemiology (STROBE) statement: guidelines for reporting observational studies. Lancet 2007;370:1453-7.

28. World Medical Association. World Medical Association Declaration of Helsinki: ethical principles for medical research involving human subjects. JAMA 2013;310:2191-4.

29. Al-Mamary M, Al-Habori M, Al-Aghbari AM, Baker MM. Investigation into the toxicological effects of Catha edulis leaves: a short term study in animals. Phytother Res $2002 ; 16: 127-32$.

30. Al-Habori M, Al-Aghbari A, Al-Mamary M, Baker M. Toxicological evaluation of Catha edulis leaves: a long term feeding experiment in animals. J Ethnopharmacol $2002 ; 83: 209-17$

31. Alsalahi A, Abdulla MA, Al-Mamary M, Noordin MI, Abdelwahab SI, Alabsi AM, et al. Toxicological features of Catha edulis (khat) on livers and kidneys of male and female Sprague-Dawley rats: A subchronic study. Evid Based Complement Alternat Med 2012;2012:829401.

32. D'Souza R, Sinnott P, Glynn MJ, Sabin CA, Foster GR. An unusual form of autoimmune hepatitis in young Somalian men. Liver Int 2005;25:325-30.

33. Pantano F, Tittarelli R, Mannocchi G, Zaami S, Ricci S, Giorgetti R, et al. Hepatotoxicity induced by "the 3Ks": Kava, kratom and khat. Int J Mol Sci 2016;17:580.

34. Buch S, Stickel F, Trepo E, Way M, Herrmann A, Nischalke HD, et al. A genome-wide association study confirms PNPLA3 and identifies TM6SF2 and MBOAT7 as risk loci for alcohol-related cirrhosis. Nat Genet 2015;47:1443-8. 
35. Date J, Tanida N, Hobara T. Qat chewing and pesticides: a study of adverse health effects in people of the mountainous areas of Yemen. Int J Environ Health Res 2004;14:405-14.

36. Mahmoud AL. Mycotoxin-producing potential of fungi associated with qat (Catha edulis) leaves in Yemen. Folia Microbiol (Praha) 2000;45:452-6.

37. Abid MD, Chen J, Xiang M, Zhou J, Chen X, Gong F. Khat (Catha edulis) generates reactive oxygen species and promotes hepatic cell apoptosis via MAPK activation. Int J Mol Med 2013;32:389-95.

38. Jones AL, Simpson KJ. Review article: mechanisms and management of hepatotoxicity in ecstasy (MDMA) and amphetamine intoxications. Aliment Pharmacol Ther $1999 ; 13: 129-33$.

39. Al-Akhali MS, Al-Moraissi EA. Khat chewing habit produces a significant adverseneffect on periodontal, oral health: A systematic review and meta-analysis. J Periodontal Res 2017;52:937-45.

40. Al-Motarreb A, Al-Habori M, Broadley KJ. Khat chewing, cardiovascular diseases and other internal medical problems: the current situation and directions for future research. $\mathrm{J}$ Ethnopharmacol 2010;132:540-8.

41. Central Statistical Agency (CSA) Ethiopia. Ethiopia demographic and health survey 2016. Addis Ababa, Ethiopia: CSA, 2016.

https://dhsprogram.com/pubs/pdf/FR328/FR328.pdf. Accessed October 24, 2017.

42. Tsega E, Nordenfelt E, Hansson BG, Mengesha B, Lindberg J. Chronic liver disease in Ethiopia: a clinical study with emphasis on identifying common causes. Ethiop Med J 1992;30(2 Suppl):1-33. 
43. Adhanom M, Desalegn H. Magnitude, clinical profile and hospital outcome of chronic liver disease at St. Paul's Hospital Millennium Medical College, Addis Ababa, Ethiopia. Ethiop Med J 2017;55:267-72.

44. Fleming KM, Aithal GP, Solaymani-Dodaran M, Card TR, West J. Incidence and prevalence of cirrhosis in the United Kingdom, 1992-2001: a general population-based study. J Hepatol 2008;49:732-8.

45. Scaglione S, Kliethermes S, Cao G, Shoham D, Durazo R, Luke A, et al. The epidemiology of cirrhosis in the United States: A population-based study. J Clin Gastroenterol 2015;49:690-6.

46. Tsochatzis EA, Bosch J, Burroughs AK. Liver cirrhosis. Lancet 2014;383:1749-61.

47. Daba D, Hymete A, Bekhit AA, Mohamed AM, Bekhit Ael-D. Multi residue analysis of pesticides in wheat and khat collected from different regions of Ethiopia. Bull Environ Contam Toxicol 2011;86:336-41. 


\section{FIGURE LEGENDS}

\section{Figure 1 - Selection of study subjects}

a Two patients refused blood sampling and withdrew their consent; three patients deteriorated rapidly and were withdrawn from the study for compassionate reasons.

${ }^{b}$ Nine patients refused blood sampling and withdrew their consent.

Abbreviations: ALT, alanine aminotransferase; CLD, chronic liver disease.
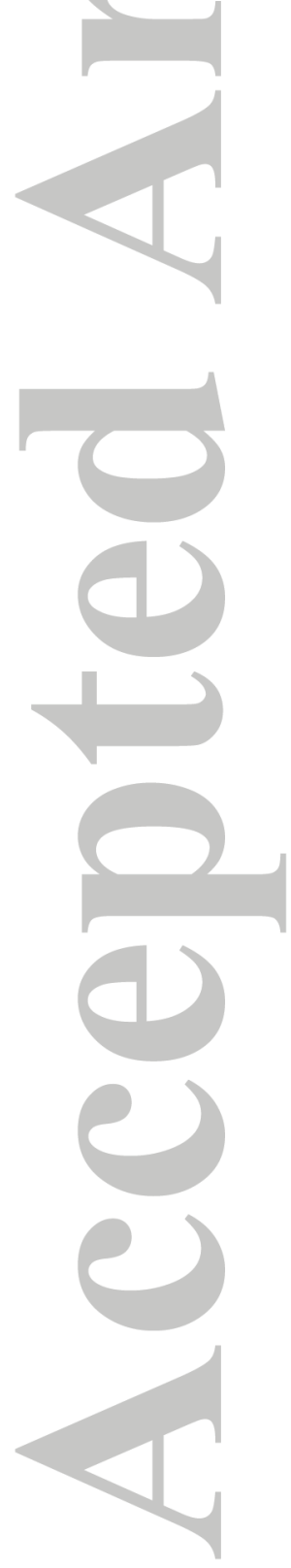

Hepatology

This article is protected by copyright. All rights reserved. 
Table 1 - Characteristics of the cases and controls included in the study

\begin{tabular}{|c|c|c|c|}
\hline Characteristic & $\begin{array}{c}\text { Cases } \\
(\mathrm{n}=150)\end{array}$ & $\begin{array}{l}\text { Controls } \\
(\mathrm{n}=300)\end{array}$ & $p$ \\
\hline en & $108(72.0)$ & $172(57.3)$ & 0.002 \\
\hline Age (years) & $30(25-40)$ & $30(24-52)$ & 0.125 \\
\hline Religion & & & $<0.001$ \\
\hline Islam & $139(92.7)$ & $198(66.0)$ & \\
\hline Christianity & $11(7.3)$ & $102(34.0)$ & \\
\hline History of alcohol consumption & & & $<0.001$ \\
\hline yer & $139(92.7)$ & $233(77.7)$ & \\
\hline Current & $6(4.0)$ & $52(17.3)$ & \\
\hline Stopped & $5(3.3)$ & $15(5.0)$ & \\
\hline Alcohol abuse ${ }^{a}$ & $3(2.0)$ & $9(3.0)$ & 0.758 \\
\hline History of khat use & $127(84.7)$ & $203(67.7)$ & $<0.001$ \\
\hline Khat years ${ }^{\text {b }}$ & $20(3-70)$ & $2(0-20)$ & $<0.001$ \\
\hline Men & $36(6-75)$ & $10(0-40)$ & \\
\hline Women & $0.6(0-7)$ & $0.1(0-5)$ & \\
\hline HBsAg positive & $55(36.7)$ & $22(7.3)$ & $<0.001$ \\
\hline Anti-HCV positive & $2(1.3)$ & $0(0.0)$ & 0.111 \\
\hline
\end{tabular}

Data are presented as number (\%) or as median (interquartile range).

${ }^{a}$ Defined as consumption of $>20$ grams alcohol per day in women and $>30$ grams per day in men.

${ }^{b}$ One khat year is defined by daily use of 200 grams of fresh khat for one year.

Abbreviations: anti-HCV, hepatitis $\mathrm{C}$ virus antibody; $\mathrm{HBsAg}$, hepatitis $\mathrm{B}$ surface antigen. 
Table 2 - The association between khat and the risk of developing chronic liver disease controlling for potential confounders

\begin{tabular}{|c|c|c|c|c|c|c|c|}
\hline \multirow{3}{*}{ Characteristic } & \multirow{2}{*}{\multicolumn{2}{|c|}{$\begin{array}{c}\text { Cases } \\
(\mathrm{n}=150) \\
\text { Khat exposure }\end{array}$}} & \multirow{2}{*}{\multicolumn{2}{|c|}{$\begin{array}{c}\begin{array}{c}\text { Controls } \\
(\mathrm{n}=300)\end{array} \\
\text { Khat exposure }\end{array}$}} & \multirow{3}{*}{$\begin{array}{c}\text { OR } \\
(95 \% \mathrm{CI})\end{array}$} & \multirow{3}{*}{$\begin{array}{c}\mathrm{OR}_{\mathrm{MH}} \\
(95 \% \mathrm{CI})\end{array}$} & \multirow{3}{*}{$\begin{array}{l}\text { Breslow and Day } \\
\text { test of homogeneity } \\
(p)\end{array}$} \\
\hline & & & & & & & \\
\hline & Yes & No & Yes & No & & & \\
\hline Crude (n) & 127 & 23 & 203 & 97 & $2.64(1.56-4.58)$ & & \\
\hline \multicolumn{8}{|l|}{ Sex } \\
\hline Men & 104 & 4 & 134 & 38 & $7.37(2.52-29.18)$ & $\star$ & 0.001 \\
\hline $18-29$ years & 47 & 10 & 71 & 57 & $3.77(1.68-9.07)$ & \multirow[t]{2}{*}{$2.57(1.55-4.28)$} & \multirow[t]{2}{*}{0.177} \\
\hline$\geq 30$ years & 80 & 13 & 132 & 40 & $1.86(0.91-4.03)$ & & \\
\hline \multicolumn{8}{|l|}{ Alcohol consumption } \\
\hline Yes & 10 & 1 & 42 & 25 & $5.95(0.75-268.43)$ & \multirow[t]{2}{*}{$2.57(1.54-4.30)$} & \multirow[t]{2}{*}{0.396} \\
\hline No & 117 & 22 & 161 & 72 & $2.38(1.36-4.26)$ & & \\
\hline Positive & 1 & 1 & 0 & 0 & $\star \star$ & & \\
\hline Negative & 126 & 22 & 203 & 97 & & & \\
\hline
\end{tabular}

$\star$ Cannot be calculated because sex is an effect modifier of khat use in chronic liver disease.

$\star \star$ Cannot be calculated since none of the controls are anti-HCV positive.

Abbreviations: Anti-HCV, hepatitis C virus antibody; CI, confidence interval; HBsAg, hepatitis B surface antigen; $\mathrm{OR}$, odds ratio; $\mathrm{OR}_{\mathrm{MH}}$ Mantel-Haenszel summary odds ratio estimate. 
Table 3 - Gradient effect of khat use on the frequency of chronic liver disease, stratified by sex

\begin{tabular}{|c|c|c|c|c|c|c|}
\hline \multirow[t]{2}{*}{$\Gamma$} & \multicolumn{3}{|c|}{$\begin{array}{c}\text { Men } \\
(n=280)\end{array}$} & \multicolumn{3}{|c|}{$\begin{array}{l}\text { Women } \\
(n=170)\end{array}$} \\
\hline & $\begin{array}{c}\text { Cases } \\
(n=108)\end{array}$ & $\begin{array}{l}\text { Controls } \\
(n=172)\end{array}$ & $\operatorname{AOR}(95 \% \mathrm{CI})^{\mathrm{a}}$ & $\begin{array}{l}\text { Cases } \\
(\mathrm{n}=42)\end{array}$ & $\begin{array}{l}\text { Controls } \\
(n=128)\end{array}$ & $\operatorname{AOR}(95 \% \mathrm{CI})^{\mathrm{a}}$ \\
\hline \multicolumn{7}{|l|}{ Khat years, by quartiles ${ }^{b}$} \\
\hline Q1:0 & 4 & 40 & 1.0 (reference) & 19 & 61 & 1.0 (reference) \\
\hline $\mathrm{Q} 2: 0.1-5.0$ & 21 & 40 & $3.58(1.05-12.21)$ & 11 & 37 & $1.21(0.48-3.06)$ \\
\hline Q3: $5.1 \neg 40.0$ & 34 & 51 & $5.90(1.79-19.44)$ & 7 & 22 & $0.98(0.32-3.00)$ \\
\hline Q4: $40.1-250$ & 49 & 41 & $13.03(3.61-47.02)$ & 5 & 8 & $1.97(0.46-8.45)$ \\
\hline$p$ for trend & & & $<0.001$ & & & 0.801 \\
\hline
\end{tabular}

Abbreviations: AOR, adjusted odds ratio; CI, confidence interval.

${ }^{a}$ Adjusted for the confounding effect of age, alcohol consumption and chronic hepatitis B infection.

${ }^{\mathrm{b}}$ One khat year is defined by daily use of 200 grams of fresh khat for one year. 


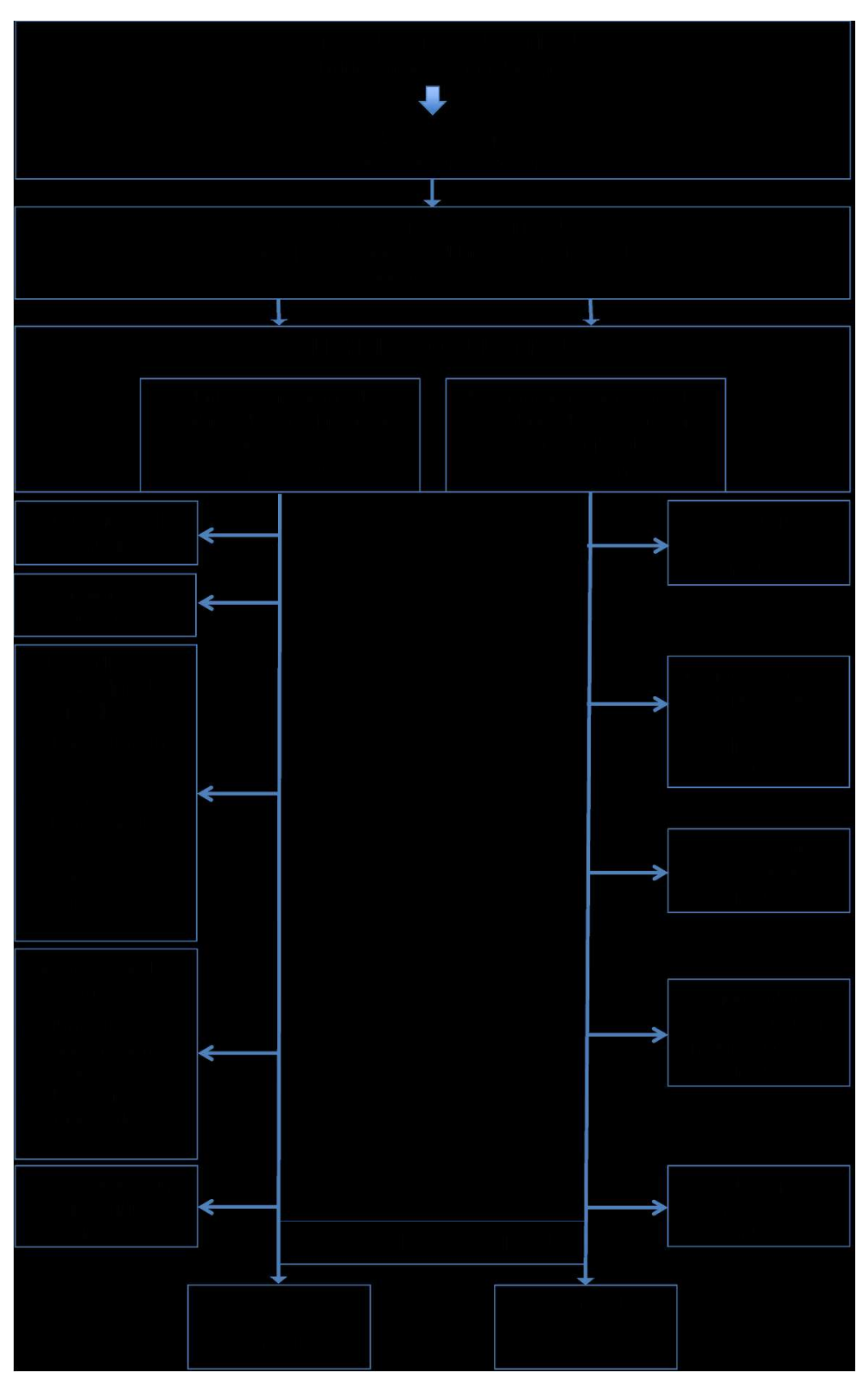

Hepatology

This article is protected by copyright. All rights reserved. 

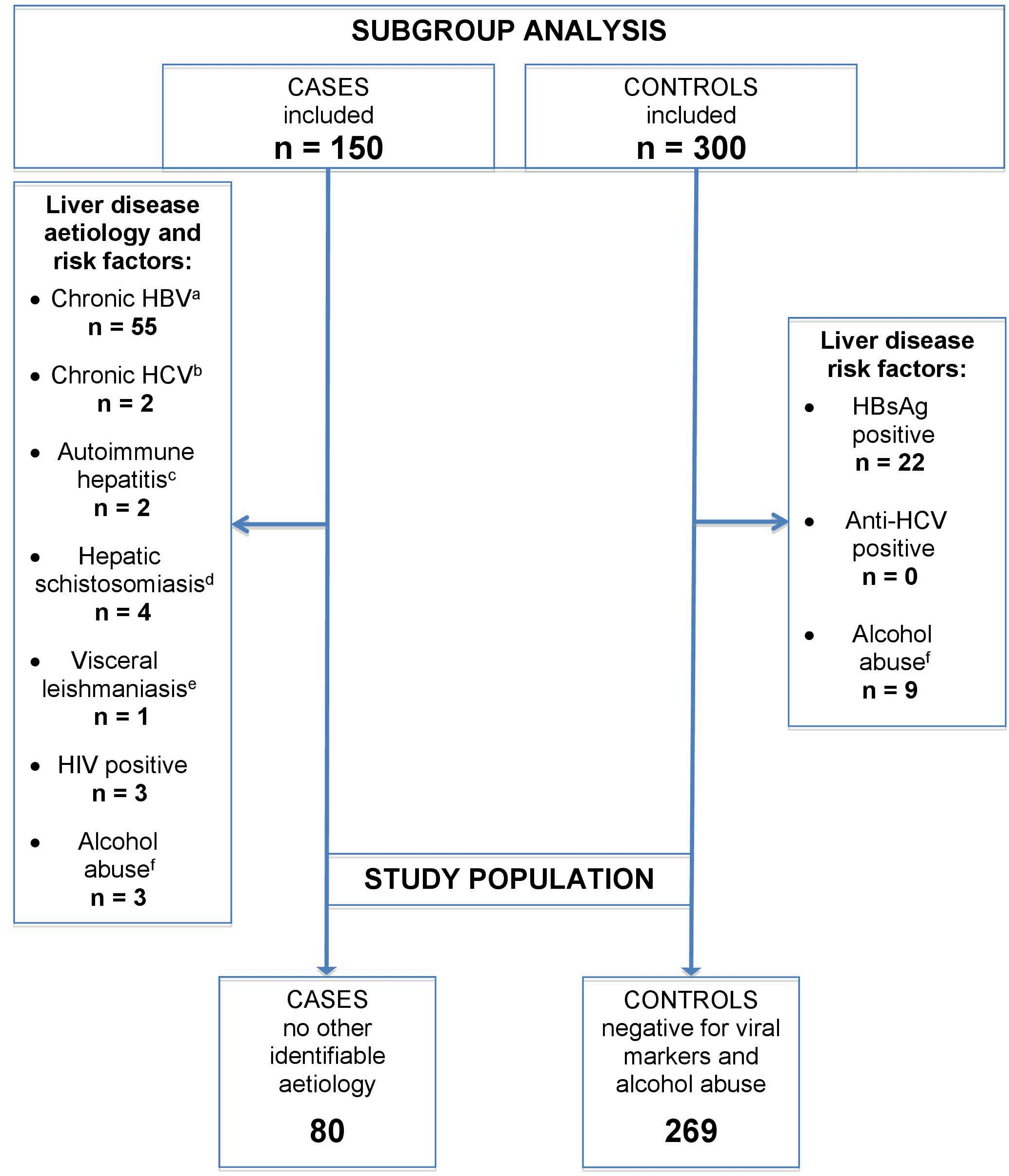

a. Defined as ultrasonographic evidence of chronic liver disease and positive HBsAg.

b. Defined as ultrasonographic evidence of chronic liver disease and positive anti-HCV.

c. Diagnosed by exclusion of alternative diagnoses and strongly positive anti-nuclear antibodies or anti-actin and elevated $\operatorname{IgG}(>1.1 \mathrm{x}$ upper limit of normal).

d. Diagnosed by finding ova from Schistosoma mansoni in stool samples and typical ultrasonographic findings of hepatic schistosomiasis confirmed by an independent expert reviewer and absence of viral markers.

e. Diagnosed by positive recombinant K39 antigen strip test and hepatosplenomegaly confirmed by abdominal ultrasound.

f. Defined as consumption of $>20$ grams alcohol per day in women and $>30$ grams per day in men. 